\title{
Combined endoscopic ultrasound-guided gastrojejunostomy and anterograde biliary stenting
}

Malignant involvement of the second portion of the duodenum and surrounding structures can create therapeutic challenges. We report a case of combined endoscopic ultrasound (EUS)-guided gastrojejunostomy (GJ) and anterograde biliary stenting in a patient with an infiltrative porta hepatis mass causing gastric outlet obstruction (GOO) and biliary obstruction.

An 83-year-old woman with gastric adenocarcinoma was found to have a malignant biliary obstruction due to infiltration of the porta hepatis and common bile duct (CBD) on magnetic resonance cholangiopancreatography ( $\mathbf{F i g} \mathbf{1}$ ). Endoscopic retrograde cholangiopancreatography was attempted, but there was clear evidence of an evolving GOO with malignant involvement of the ampullary region.

We proceeded with combined EUS-G] and EUS-guided gastrohepatic access with anterograde biliary stenting. The endoscope was advanced beyond the obstruction, and the duodenum distal to the ligament of Treitz was distended with saline, contrast, and methylene blue. The jejunum was identified on EUS and confirmed with needle aspiration. A 15-mm AXIOS electrocautery-enhanced lumenapposing metal stent (Boston Scientific, Marlborough, Massachusetts, USA) was deployed under EUS guidance; egress of methylene blue confirmed successful placement.

To address the biliary obstruction, a dilated left hepatic biliary radical was identified and punctured with a 19-gauge needle. Cholangiogram was notable for CBD stricture. A 0.025-inch guidewire was advanced anterograde into the duodenum. To facilitate anterograde stent deployment, and because there are no cystotomes readily available in the USA, the AXIOS catheter was reset and used over the wire to create a tract. This allowed for anterograde placement of an un-

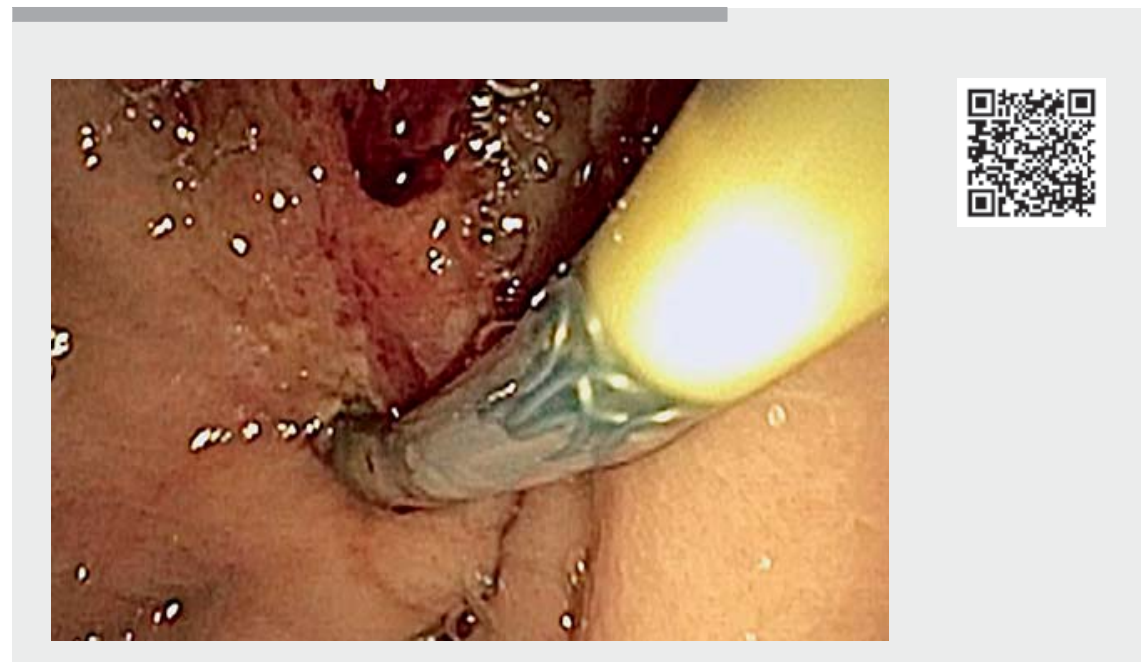

Video 1 Combined endoscopic ultrasound-guided gastrojejunostomy and anterograde biliary stenting for treatment of malignant obstruction involving the duodenum and bile duct.

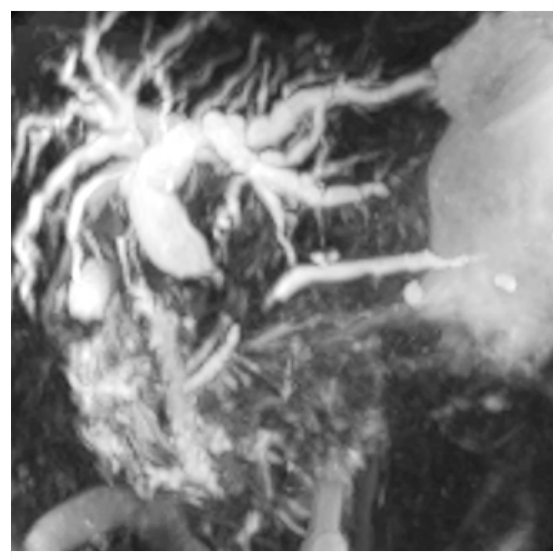

- Fig. 1 Magnetic resonance cholangiopancreatography revealed an ill-defined infiltrative mass, approximately $5 \times 4 \mathrm{~cm}$, involving the gastric pylorus. The mass was causing extrinsic compression of the common bile duct with upstream dilatation.

covered $10 \times 80-\mathrm{mm}$ biliary metal stent across the biliary stricture ( $\vee$ Fig. 2 ). The puncture site was closed with an overthe-scope clip ( $\triangleright$ Video 1 ).

The patient tolerated the procedure without complications and was dis-

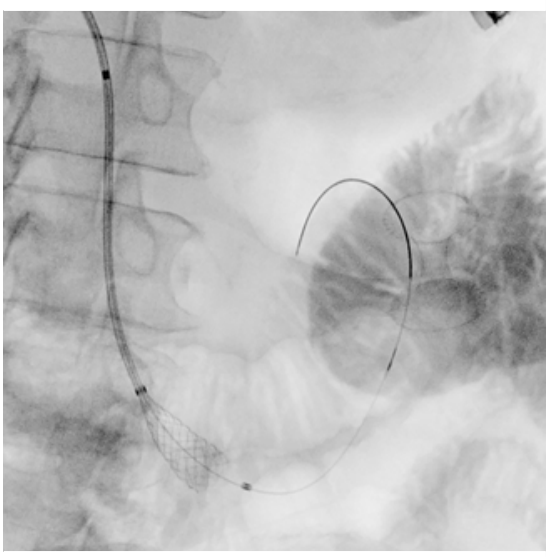

- Fig. 2 Anterograde placement of an uncovered biliary self-expandable metal stent across the distal biliary stricture.

charged to a hospice. This report highlights how EUS can be used for a combined biliary and luminal obstruction, with the reuse of an electrocautery-enhanced catheter for stent delivery.

Endoscopy_UCTN_Code_TTT_1AS_2AG 


\section{Competing interests}

The authors declare that they have no conflict of interest.

The authors

Michael Ma ${ }^{1} \odot$, Daniel Hogan ${ }^{1} \odot$, Arvind J. Trindade $^{2}$, Evin McCabe ${ }^{1}$, Petros Benias ${ }^{1}$

1 Division of Gastroenterology, Lenox Hill Hospital, New York, New York, United States

2 Division of Gastroenterology, Long Island Jewish Medical Center, New Hyde Park, New York, United States
Corresponding author

\section{Michael Ma, MD}

Division of Gastroenterology, Lenox Hill Hospital, Northwell Health, 100 E. 77th St., 2nd Floor, Lachman Pavilion, New York, NY 10075, United States

mma1@Northwell.edu

Bibliography

Endoscopy 2022; 54: E277-E278

DOI 10.1055/a-1499-6234

ISSN 0013-726X

published online 18.6.2021

(C) 2021. Thieme. All rights reserved.

Georg Thieme Verlag KG, Rüdigerstraße 14

70469 Stuttgart, Germany
ENDOSCOPY E-VIDEOS

https://eref.thieme.de/e-videos

回回 Endoscopy E-Videos is an open access online section, 回: reporting on interesting cases and new techniques in gastroenterological endoscopy. All papers include a high quality video and all contributions are freely accessible online. Processing charges apply (currently EUR 375), discounts and wavers acc. to HINARI are available.

This section has its own submission website at

https://mc.manuscriptcentral.com/e-videos 